\title{
ANALISIS PENGARUH STRATEGI ADAPTASI TERHADAP KINERJA UMKM DI KABUPATEN MAMUJU
}

\author{
Hari Yeni*1, J.Fuji Inzani SL ${ }^{2}$ \\ 1,2Jurusan Manajemen, STIE Muhammadiyah Mamuju \\ e-mail: *1․ㅐariyeni7@gmail.com, ${ }^{2}$ fujiinzani9@gmail.com
}

\begin{abstract}
Abstrak
Wabah Covid-19 membawa perubahan pada setiap lini kehidupan termasuk aktivitas pelaku Usaha Mikro Kecil Menengah (UMKM). Para pelaku UMKM diharapkan dapat beradaptasi dengan perubahan yang terjadi untuk meminimalisir dampak lanjutan dari pandemi seperti pemutusan hubungan kerja ataupun penutupan usaha. Upaya untuk beradaptasi perlu dilakukan secara sistematis dan strategis agar pelaku UMKM tidak kesulitan apabila menghadapi kondisi serupa serta sebagai bagian dari pola bisnis jangka panjang. Oleh karena itu penelitian ini bertujuan untuk mengetahui pengaruh strategi adaptasi terhadap kinerja UMKM baik dari segi adaptasi produk maupun pemasaran. Metode penelitian menggunakan metode kuantitatif menerapkan model regresi linear berganda untuk menguji hipotesis yang diajukan dengan terlebih dahulu memastikan data yang dikumpulkan telah memenuhi uji validitas, reliabilitas, dan asumsi klasik. Hasil penelitian menunjukkan bahwa strategi adaptasi produk dan pemasaran berpengaruh secara parsial $\left(\mathrm{t}_{\text {hitung }}>\mathrm{t}_{\text {tabel }} ; p<0,05\right)$ maupun simultan $\left(\mathrm{F}_{\text {hitung }}>\mathrm{F}_{\text {tabel }} ; p<0,05\right)$ terhadap kinerja UMKM di Kabupaten Mamuju dimana faktor dominan yang memengaruhi yaitu strategi adaptasi pemasaran. Berdasarkan hasil tersebut maka dapat disarankan kepada pelaku UMKM untuk melakukan adaptasi pemasaran dengan memanfaatkan berbagai saluran pemasaran yang tersedia agar mampu meningkatkan kinerja serta melakukan adaptasi produk berdasarkan respon pasar.
\end{abstract}

Kata kunci : Adaptasi, Produk, Pemasaran, Pandemi

The Covid-19 outbreak has brought changes to every line of life, including the activities of Micro, Small and Medium Enterprises (MSMEs). MSME actors are expected to be able to adapt to changes that occur to minimize the continued impact of the pandemic, such as termination of employment or business closures. The MSME actor adaption need to be carried out systematically and strategically so they do not have problems when facing similar conditions and as part of a long-term business pattern. Therefore, this study aimed to determine the effect of adaptation strategies on the performance of SMEs, product adaptation and marketing. The research method was used quantitative methods to apply multiple linear regression models to test the proposed hypothesis by first ensuring that the data collected has met the validity, reliability, and classical assumptions. The results showed that the product and marketing adaptation strategy had a partial $\left(t_{\text {count }}>t_{\text {table }} ; p<0.05\right)$ and simultaneous $\left(F_{\text {count }}>F_{\text {table }} ; p<0.05\right)$ performance on the performance of MSMEs in Mamuju Regency where the dominant factor influencing was the marketing adaptation strategy. Based on these results, it can be suggested to MSME actors to adapt marketing by utilizing various available marketing channels in order to be able to improve performance and adapt products based on market response.

Keywords : Adaptation, Product, Marketing, Pandemic

\section{PENDAHULUAN}

Berdasarkan data Kementerian Koperasi dan UMKM, terdapat kurang lebih 163.713 pelaku UMKM yang terdampak pandemi (Rosita, 2020). Adapun berbagai permasalahan yang dihadapi oleh UMKM yaitu $56 \%$ melaporkan penurunan penjualan, 
$22 \%$ melaporkan permasalahan aspek pembiayaan, $15 \%$ terkait distribusi barang, dan $4 \%$ melaporkan kesulitan mendapatkan bahan baku (Pakpahan, 2020). Untuk mengatasi permasalahan tersebut maka para pelaku UMKM dan pemerintah perlu menyusun strategi masing-masing yang saling mendukung satu sama lain (Hidayat dkk., 2021).

Strategi pemerintah dalam mengantisipasi dampak ekonomi akibat pandemi Covid19 dikenal dengan istilah Delapan Program Khusus Kementrian Koperasi dan UKM. Program tersebut adalah: (1) stimulus sekitar Rp 2 Triliun untuk meningkatkan daya beli produk UMKM, (2) usaha dapat berjalan dengan menerapkan social distancing, (3) restrukturisasi dan subsidi suku bunga kredit usaha mikro, (4) restrukturisasi kredit khusus bagi koperasi melalui LPDP KUMKM, (5) stimulasi UMKM di daerah untuk memproduksi Alat Pelindung Diri (APD), (6) memasukan pelaku UMKM ke dalam klaster rentan terdampak Covid-19 (penerima kartu pra-kerja), (7) bantuan langusng tunai, dan (8) Pph 21, pajak penghasilan impor, Pph 25 dan restitusi nilai dapat direlaksasi untuk UMKM.

Selain dibantu oleh pemerintah, UMKM juga menerapkan berbagai strategi untuk beradaptasi dengan konsep normal baru yang diusung oleh pemerintah. Menurut Bennet, pencetus strategi adaptasi, strategi adaptasi adalah pola yang dibentuk melalui berbagai penyesuian yang terencana untuk meperoleh sumber daya dan memecahkan masalah yang dihadapi. Adapun pola yang perlu ditinjau pada penyusunan strategi adaptasi yaitu polapola perilaku dan tindakan (Ahimsa, 2003). Melalui strategi adaptasi maka diharapkan kinerja UMKM kembali pada kondisi normal.

Penelitian terdahulu yang dilakukan oleh Amri (2020) menunjukkan bahwa UMKM yang bergerak di sektor pariwisata terkena dampak pandemi paling signfikan yang kemudian disusul oleh sektor penyedia makanan, minuman, dan usaha kreatif. Penelitian Narto dan Gatot (2020) menyimpulkan bahwa strategi yang sesuai untuk bertahan di tengah pandemi yaitu dengan mempertahankan harga serta melakukan promosi digital (adaptasi pemasaran) dan meningkatkan kualitas produk (adaptasi produk). Barisa (2021) dalam penelitiannya menggambarkan bahwa terdapat perbedaan strategi antara usaha perdagangan yang terkena dampak dan tidak terkena dampak dimana pada unit usaha yang terkena dampak beradaptasi dengan mengurangi suplai barang untuk menghindari kerugian. Oleh karena itu hipotesis yang akan diuji dan dikembangkan pada penelitian ini yaitu :

H1 : Strategi adaptasi produk berpengaruh signfikan terhadap kinerja UMKM

H2 : Strategi adaptasi pemasaran berpengaruh signifikan terhadap kinerja UMKM

H3 : Strategi adaptasi produk dan pemasaran berpengaruh simultan terhadap kinerja UMKM

H4 : Strategi adaptasi pemasaran sebagai faktor dominan

\section{METODE PENELITIAN}

Jenis data pada penelitian secara umum terbagi dua yaitu data kuantitatif berupa maupun data kualitatif berupa pernyataan terkait variabel penelitian. Pengumpulan data pada penelitian ini bersumber dari responden penelitian (data primer) maupun literatur lain yang terkait (data sekunder).

Penentuan sampel penelitian menggunakan simple random sampling dan jumlah responden diestimasi berdasarkan populasi pelaku UMKM di Kabupaten Mamuju yaitu sebanyak 235 UMKM (mamjukab.go.id, 2020). Berdasarkan hasil perhitungan rumus 


\section{AkMen

slovin dengan tingkat kesalahan $5 \%(\alpha=0,05)$ maka diperoleh jumlah responden yang mewakili populasi yaitu sbanyak 148 pelaku UMKM.

Analisis data pada penelitian ini dilakukan secara bertahap yaitu analisis deskriptif dan pengujian hipotesis dengan uji-t (parsial) dan uji-F (simultan) menggunakan model regresi linear berganda. Uji-t digunakan untuk menguji $\mathrm{H} 1$ dan $\mathrm{H} 2$ sedangkan uji-F untuk menguji H3. Untuk membantu proses analisis data maka penulis menggunakan program Statistical Package for Sosial Science (SPSS) versi 22. Adapun model regresi yang digunakan dapat diperhatikan pada persamaan berikut.

Keterangan :

$$
Y=a+b_{1} X_{1}+b_{2} X_{2}+e
$$

$Y \quad$ : Kinerja UMKM

a : Konstanta

$b_{1}, b_{2}$ : Koefisien regresi

$X_{1} \quad$ : Strategi Adaptasi Produk

$X_{2} \quad$ : Strategi Adaptasi Pemasaran

e : Galat

\section{HASIL DAN PEMBAHASAN}

Hasil

Responden pada penelitian ini merupakan para pelaku UMKM yang memiliki karakteristik bervariasi. Tabel berikut menunjukkan jenis usaha responden penelitian.

Tabel 1. Jenis usaha responden

\begin{tabular}{|c|c|c|}
\hline Jenis Usaha & Frekuensi & Persentase \\
\hline Campuran & 46 & $31 \%$ \\
\hline Kuliner & 32 & $22 \%$ \\
\hline Fashion & 11 & $7 \%$ \\
\hline Pertanian & 5 & $3 \%$ \\
\hline Perikanan & 13 & $9 \%$ \\
\hline Jasa & 41 & $28 \%$ \\
\hline Total & 148 & $100 \%$ \\
\hline
\end{tabular}

Sumber : Data diolah, 2021

Berdasarkan Tabel 1 maka dapat diketahui bahwa struktur UMKM di Kabupaten Mamuju didominasi oleh pedagang campuran (kios/toko) (31\%), penyedia jasa (28\%), dan pedagang kuliner $(22 \%)$. Struktur tersebut menunjukkan adanya perubahan corak ekonomi dimana sebelum menjadi ibu kota provinsi, Kabupaten Mamuju masih didominasi oleh usaha pertanian dan perikanan.

Selain jenis usaha, lama usaha responden dapat memengaruhi persepsi pelaku UMKM menyikapi pandemi. Tabel berikut menunjukkan lama usaha responden penelitian.

Tabel 2. Lama usaha responden

\begin{tabular}{|c|c|c|}
\hline Lama Usaha & Frekuensi & Persentase \\
\hline$<1$ tahun & 15 & $10 \%$ \\
\hline $1-5$ tahun & 44 & $30 \%$ \\
\hline $6-10$ tahun & 56 & $38 \%$ \\
\hline$>10$ tahun & 33 & $22 \%$ \\
\hline Total & 148 & $100 \%$ \\
\hline
\end{tabular}


Mayoritas responden penelitian telah menekuni usahanya selama lebih dari 5 (lima) tahun dengan rincian 38\% selama 6-10 tahun dan 22\% selama lebih dari 10 tahun. Kondisi pandemi sejak awal tahun 2020 ternyata tidak menutup peluang usaha di Kabupaten Mamuju dimana terdapat $10 \%$ responden yang baru membuka usahanya dalam setahun terakhir.

Untuk mengetahui ketepatan dan kehandalan alat ukur yang digunakan maka perlu dilakukan uji validitas dan reliabilitas data. Hasil uji validitas dan reliabilitas dapat diperhatikan pada tabel berikut.

Tabel 3. Hasil uji validitas dan reliabilitas variabel Strategi Adaptasi Produk

\begin{tabular}{|l|c|c|}
\hline \multicolumn{1}{|c|}{ Parameter } & $\mathrm{r}_{\text {hitung }}$ & Cronbach alpha \\
\hline Penyesuaian fasilitas & 0,461 & \multirow{2}{*}{0,721} \\
\cline { 1 - 2 } Ketersediaan fasilitas protkes & 0,858 & \\
\hline Sterilisasi peralatan & 0,512 & \\
\hline Sumber bahan baku & 0,410 & \\
\cline { 1 - 2 } Jumlah bahan baku & 0,358 & \\
\hline Perencanaan produk & 0,622 & \\
\hline Sterilisasi produk & 0,715 & \\
\hline Standarisasi produk & 0,810 & \\
\hline
\end{tabular}

Sumber : Data diolah, 2021

Tabel 4. Hasil uji validitas dan reliabilitas variabel Strategi Adaptasi Pemasaran

\begin{tabular}{|l|c|c|}
\hline \multicolumn{1}{|c|}{ Parameter } & r $_{\text {hitung }}$ & Cronbach alpha \\
\hline $\begin{array}{l}\text { Penyesuaian produk dan kebutuhan } \\
\text { masa pandemi }\end{array}$ & 0,420 & 0,842 \\
\hline Penyesuaian harga & 0,815 & \\
\hline $\begin{array}{l}\text { Pembatasan wilayah distribusi } \\
\text { produk }\end{array}$ & 0,853 & \\
$\begin{array}{l}\text { Penerapan protkes pada proses } \\
\text { distribusi }\end{array}$ & 0,866 & \\
\hline Penyesuaian anggaran promosi & 0,792 & \\
\hline Perubahan metode promosi & 0,850 & \\
\hline $\begin{array}{l}\text { Penyesuaian jumlah SDM untuk } \\
\text { promosi }\end{array}$ & 0,344 & \\
\hline
\end{tabular}

Sumber : Data diolah, 2021

Tabel 5. Hasil uji validitas dan reliabilitas variabel Kinerja UMKM

\begin{tabular}{|l|c|c|}
\hline \multicolumn{1}{|c|}{ Parameter } & $\mathrm{r}_{\text {hitung }}$ & Cronbach alpha \\
\hline Peningkatan penjualan & 0,340 & 0,615 \\
\hline Tren perolehan laba & 0,655 & \\
\hline Penyesuaian modal & 0,710 & \\
\hline Konsistensi kualitas produk & 0,733 & \\
\hline Rencana usaha berjalan lancar & 0,442 & \\
\hline Laba usaha mencukupi operasional & 0,513 & \\
\hline
\end{tabular}


Sumber : Data diolah, 2021

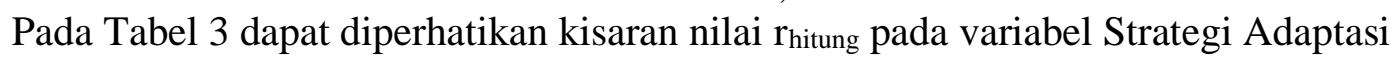
Produk yaitu 0,358-0,858 dengan nilai Cronbach alpha sebesar 0,721. Pada Tabel 4, kisaran nilai $r_{\text {hitung }}$ pada variabel Strategi Adaptasi Pemasaran yaitu 0,344-0,866 dengan nilai Cronbach alpha sebesar 0,842. Berdasarkan Tabel 5 maka diketahui bahwa nilai

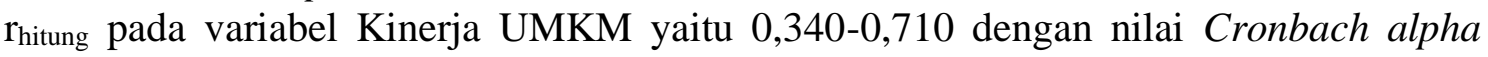
sebesar 0,615. Berdasarkan kisaran nilai $r_{\text {hitung }}$ pada setiap parameter yang lebih besar dari 0,300 dan kisaran nilai Cronbach alpha yang secara keseluruhan lebih besar dari 0,600 maka dapat dinyatakan bahwa instrumen penelitian yang digunakan memenuhi kriteria validitas dan reliabilitas.

Agar hasil uji hipotesis menggunakan model regresi linear berganda dapat memberi hasil yang tepat dan tidak bias serta mewakili populasi penelitian maka perlu dilakukan uji asumsi klasik. Asumsi klasik yang harus dipenuhi oleh suatu model regresi yaitu normalitas, multikolinearitas, dan heterokedastisitas. Hasil uji normalitas dapat diperhatikan di grafik pada gambar berikut.

\section{Gambar 1. Hasil uji normalitas}

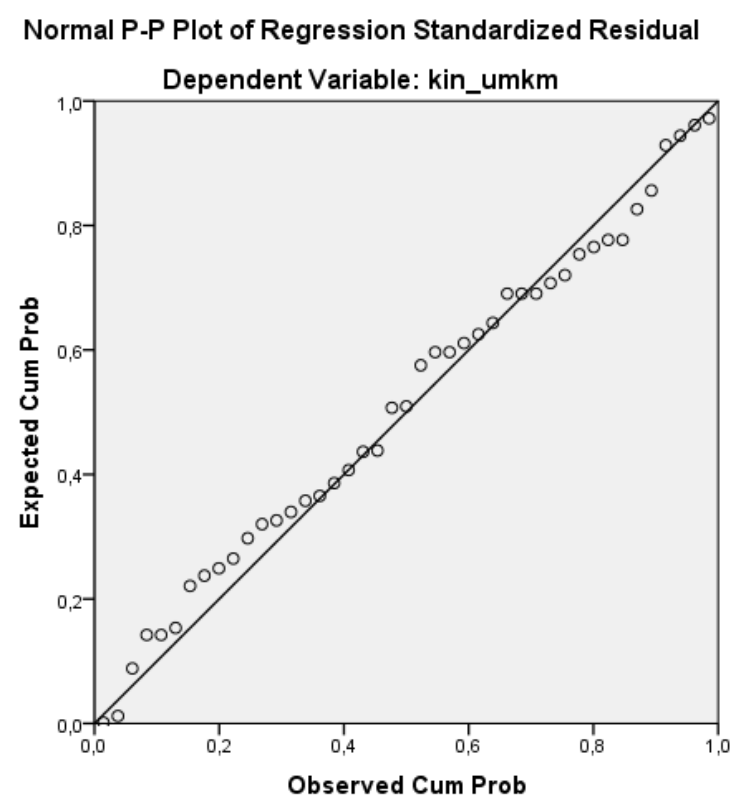

Pada Gambar 1, dapat diperhatikan bahwa residual data tersebar di sekitar garis diagonal yang menunjukkan nilai rata-rata variabel penelitian. Berdasarkan sebaran tersebut maka dapat disimpulkan bahwa data yang diperoleh dari responden telah terdistribusi secara normal dan dapat dinyatakan mewakili populasi. Hasil pengujian multikolinearitas dapat diperhatikan pada tabel berikut.

Tabel 6. Hasil uji multikolinearitas

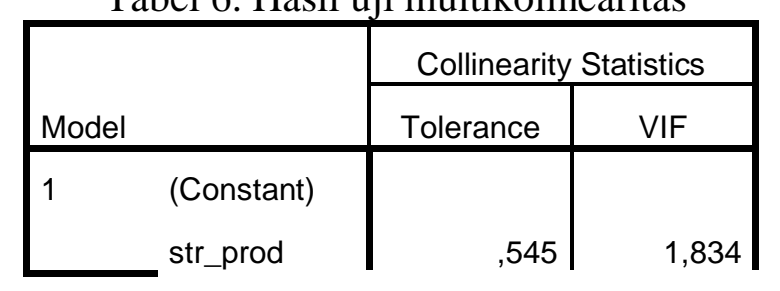




\section{AkMen

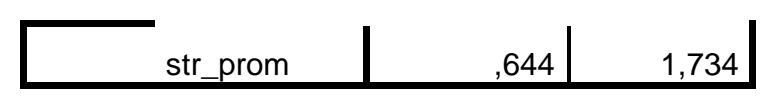

a. Dependent Variable: kin_umkm

Sumber : Data diolah, 2021

Pada Tabel 6, diperoleh nilai Tolerance pada kedua variabel lebih besar dari 0,05 dan nilai variance inflation factor (VIF) kurang dari 10 sehingga dapat dinyatakan bahwa kedua variabel independen yang diteliti tidak memiliki korelasi kuat atau saling bebas. Oleh karena itu kedua variabel bebas tersebut dapat menjadi prediktor yang baik terhadap variabel terikat (Kinerja UMKM). Adapun hasil pengujian heterokedastisitas dapat diperhatikan di grafik pada gambar berikut.

Gambar 2. Hasil uji heterokedastisitas

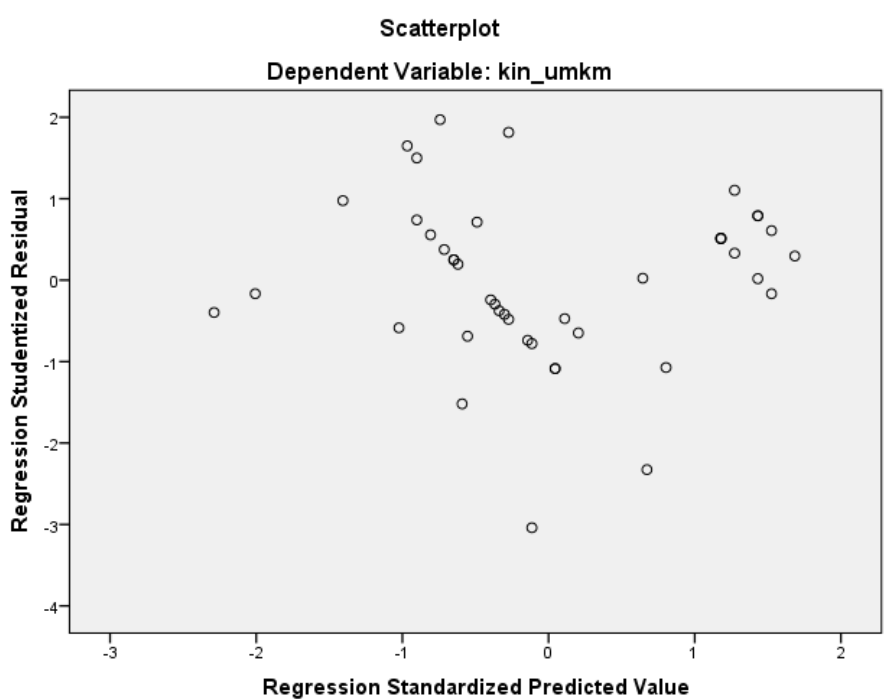

Pada Gambar 2, dapat diamati bahwa sebaran nilai residu varians tersebar secara merata di bagian atas-bawah dan kiri-kanan dari angka 0 baik pada sumbu-X maupun sumbu-Y. Oleh karena itu dapat disimpulkan bahwa model yang akan digunakan telah memenuhi asumsi heterokedastisitas.

Hipotesis yang diajukan pada penelitian ini akan diuji menggunakan uji-t dan uji-f untuk menguji $\mathrm{H} 1, \mathrm{H} 2$, dan $\mathrm{H} 3$ serta menghitung nilai sumbangan efektif untuk menjawab H4. Hasil uji-t dapat diperhatikan pada tabel berikut.

Tabel 7. Hasil uji-t

\begin{tabular}{|c|c|c|c|c|c|c|}
\hline \multirow{2}{*}{\multicolumn{2}{|c|}{ Model }} & \multicolumn{2}{|c|}{ Unstandardized Coefficients } & \multirow{2}{*}{$\begin{array}{c}\text { Standardized } \\
\text { Coefficients } \\
\text { Beta }\end{array}$} & \multirow[b]{2}{*}{$\mathrm{t}$} & \multirow[b]{2}{*}{ Sig. } \\
\hline & & $\mathrm{B}$ & Std. Error & & & \\
\hline \multirow[t]{3}{*}{1} & (Constant) & 0,945 & 2,437 & & 0,388 & 0,700 \\
\hline & str_prod & 0,239 & 0,092 & 0,254 & 2,594 & 0,013 \\
\hline & str_prom & 0,645 & 0,091 & 0,698 & 7,121 & 0,000 \\
\hline
\end{tabular}

a. Dependent Variable: kin_umkm 

berikut :

Sumber : Data diolah, 2021

Berdasarkan hasil uji-t pada Tabel 7 maka dapat diuraikan interpretasi sebagai

1. Pada kondisi konstan yaitu variabel independen tidak mengalami perubahan maka kinerja UMKM di Kabupaten Mamuju memiliki peluang peningkatan sebesar 0,945 namun peningkatan tersebut tidak signifikan sebab nilai Sig. yang diperoleh lebih besar dari 0,05

2. Koefisien regresi variabel Strategi Adaptasi Produk sebesar $+0,239$ sehingga dapat diinterpretasikan bahwa peningkatan Strategi Adaptasi Produk dapat meningkatkan Kinerja UMKM sebesar 0,239 dengan pengaruh yang signifikan (nilai Sig. $<0,05)$ dan nilai $t_{\text {hitung }}(2,594)>t_{\text {tabel }}(1,976)$ maka hipotesis pertama $(\mathrm{H} 1)$ penelitian dapat diterima

3. Koefisien regresi variabel Strategi Adaptasi Pemasaran sebesar +0,645 sehingga dapat diinterpretasikan bahwa peningkatan Strategi Adaptasi Pemasaran dapat meningkatkan Kinerja UMKM sebesar 0,645 dengan tingkat pengaruh yang signifikan (nilai Sig. $<0,05)$ dan nilai $t_{\text {hitung }}(7,121)>$ $t_{\text {tabel }}(1,976)$ sehingga hipotesis kedua $(\mathrm{H} 2)$ penelitian dapat diterima ini.

Untuk menjawab hipotesis ketiga (H3) penelitian maka berikut ini tabel hasil uji-f berikut

Tabel 8. Hasil uji-f

ANOVA $^{a}$

\begin{tabular}{|rl|r|r|r|r|r|}
\hline Model & & Sum of Squares & Df & Mean Square & F & Sig. \\
\hline 1 & Regression & 273,090 & 3 & 136,545 & 75,489 & $0,000^{\mathrm{b}}$ \\
& Residual & 72,352 & 144 & 1,809 & & \\
Total & 345,442 & 147 & & & \\
\end{tabular}

a. Dependent Variable: kin_umkm

b. Predictors: (Constant), str_prom, str_prod

Sumber : Data diolah, 2021

Pada Tabel 8 dapat diperhatikan bahwa nilai signifikansi yang diperoleh sebesar 0,000 dimana nilai tersebut lebih kecil dari taraf kesalahan yang ditolerir yaitu 5\% $(\alpha=$ $0,05)$ dan nilai $F_{\text {hitung }}(75,489)>$ Ftabel $(2,667)$. Oleh karena itu maka hipotesis ketiga (H3) penelitian diterima bahwa strategi adaptasi produk dan adaptasi pemasaran berpengaruh secara simultan terhadap kinerja UMKM di Kabupaten Mamuju.

Untuk mengetahui ketepatan model yang digunakan maka dilakukan perhitungan koefisien determinan dengan mengacu pada nilai $\mathrm{R}$ square. Berikut ini tabel nilai $\mathrm{R}$ square dari model penelitian.

Tabel 9. Nilai R square

\begin{tabular}{|c|c|c|c|}
\hline \multicolumn{4}{|c|}{ Model Summary } \\
\hline Model & $\mathrm{R}$ & R Square & $\begin{array}{c}\text { Adjusted R } \\
\text { Square }\end{array}$ \\
\hline 1 & $0,889^{a}$ & 0,791 & 0,780 \\
\hline
\end{tabular}




\title{
AkMen

\begin{abstract}
a. Predictors: (Constant), str_prom, str_prod
b. Dependent Variable: kin_umkm
\end{abstract}

Sumber : Data diolah, 2021

Berdasarkan nilai $\mathrm{R}$ square pada Tabel 9 sebesar 0,791 maka nilai koefisien determinan dari model penelitian yaitu sebesar 79,1\%. Nilai tersebut menunjukkan bahwa model yang digunakan untuk menguji hipotesis sudah baik dimana Strategi Adaptasi Produk dan Strategi Adaptasi Pemasaran mampu menjelaskan 79,1\% bagian dari Kinerja UMKM di Kabupaten Mamuju sedangkan 20,9\% sisanya dipengaruhi oleh faktor lain yang tidak diteliti.

\section{Sumbangan efektif}

Perhitungan sumbangan efektif (SE) dari setiap variabel independen mengacu pada nilai korelasinya terhadap variabel dependen dan nilai koefisien regresi yang diperoleh dari hasil uji-t. Untuk lebih jelasnya dapat diperhatikan pada tabel berikut.

Tabel 10. Sumbangan efektif variabel

\begin{tabular}{|l|c|c|c|}
\hline \multicolumn{1}{|c|}{ Variabel } & $\mathrm{r}_{\mathrm{xy}}$ & $\mathrm{B}$ & $\mathrm{SE}$ \\
\hline Strategi adaptasi produk & 0,725 & 0,254 & $18,42 \%$ \\
\hline Strategi adaptasi pemasaran & 0,869 & 0,698 & $60,66 \%$ \\
\hline
\end{tabular}

Sumber : Data diolah, 2021

Besaran nilai sumbangan efektif (SE) menunjukkan kontribusi setiap variabel independen terhadap variabel dependen. Hasil estimasi nilai SE menunjukkan bahwa variabel Strategi Adaptasi Pemasaran memiliki nilai SE lebih tinggi dibandingkan Strategi Adaptasi Produk (18,42\%). Oleh karena itu maka dapat disimpulkan bahwa variabel Strategi Adaptasi Pemasaran merupakan faktor dominan yang memengaruhi Kinerja UMKM di Kabupaten Mamuju sehingga hipotesis keempat (H4) dapat diterima.

\section{Pembahasan}

Strategi merupakan suatu proses yang menentukan adanya perencanaan terhadap para top manajer yang sungguh berarah pada tujuan jangka panjang organisasi yang disertai dengan penyusunan upaya bagaimana agar mencapai tujuan yang diharapkan (Taufiqurokhman, 2016). Oleh karena itu strategi perlu dikelola dengan baik dalam satu rangkaian keputusan dan tindakan untuk mencapai tujuan organisasi (Pearce \& Robinson, 2008).

Secara teoritik, strategi adaptasi merupakan bagian dari manajemen strategi yang diterapkan ketika seseorang/kelompok menghadapi kondisi eksternal yang tidak dapat dikendalikan seperti pandemi. Hasil penelitian menunjukkan bahwa para pelaku UMKM telah melakukan manajemen strategi menghadapi masa pandemi dengan menerapkan strategi adaptasi baik pada produk dan pemasaran dengan tujuan meningkatkan kinerja yang merupakan tujuan utama dari pelaku UMKM.

Hasil penelitian menunjukkan bahwa perencanaan dan penerapan strategi adaptasi produk berpengaruh signifikan dan dapat meningkatkan kinerja UMKM. Hasil tersebut sejalan dengan temuan Bhayangkari (2011) yang mengungkapkan bahwa adaptasi produk berhubungan dengan upaya pengusaha untuk mempertahankan 
eksistensinya dengan melakukan penyesuaian jenis produk sesuai preferensi pasar. Preferensi pasar pada masa pandemi Covid-19 tentu berbeda dengan kondisi pasar pada waktu normal sehingga para pelaku UMKM diharapkan untuk melakukan adaptasi produk agar mampu mempertahankan eksistensi dan meningkatkan kinerja UMKM sesuai kondisi pasar pada masa pandemi.

Selain adaptasi produk, pelaku UMKM di lokasi penelitian juga telah menerapkan adaptasi pemasaran. Hasil penelitian menunjukkan bahwa strategi adaptasi pemasaran berpengaruh signifikan dengan arah positif terhadap kinerja UMKM. Hasil tersebut sejalan dengan penelitian terdahulu oleh Joko \& Sutrisno (2019) dan Rosmadi (2021) bahwa adaptasi pemasaran berpengaruh signifikan terhadap pengembangan usaha. Adanya pembatasan sosial di masa pandemi menyebabkan para pelaku UMKM harus memasarkan produknya secara online dengan memanfaatkan media sosial atau market place.

Hasil penelitian menunjukkan bahwa strategi adaptasi produk dan pemasaran berpengaruh signifikan secara simultan terhadap kinerja UMKM dimana strategi adaptasi pemasaran menjadi faktor dominan. Adanya aktivitas pemasaran secara daring juga memungkinkan pelaku UMKM untuk melakukan pendataan terkait preferensi pasar dan daya beli konsumen di masa pandemi sehingga pelaku UMKM dapat melakukan adaptasi produk maupun penyesuaian harga jual atau program promosi. Oleh karena itu pada tahap implementasi strategi adaptasi di masa pandemi sebaiknya pelaku UMKM terlebih dahulu melakukan adaptasi pemasaran untuk memperoleh data akurat terkait produk dan harga yang sifatnya dinamis pada masa pandemi.

Tantangan dalam menerapkan strategi adaptasi pemasaran yaitu belum meratanya kapasitas dan kapabilitas setiap UMKM dalam memanfaatkan sarana IT. Hidayat dkk. (2021) menguraikan bahwa faktor utama yang dapat mendukung upaya resiliensi UMKM yaitu kompetensi kewirausahaan pelaku UMKM dan kemampuan memanfaatkan teknologi. Oleh karena itu diharapkan peran pemerintah untuk membantu pelaku UMKM, tidak hanya dengan bantuan modal namun juga melalui pelatihan yang terkait dengan strategi adaptasi pada masa pandemi (Utami dkk., 2021).

\section{KESIMPULAN}

Kesimpulan pada penelitian ini disusun berdasarkan hasil uji hipotesis dan pembahasan yang telah diuraikan. Kesimpulan penelitian dijabarkan sebagai berikut :

1. Strategi adaptasi produk memengaruhi kinerja UMKM secara signifikan di Kabupaten Mamuju pada masa pandemi Covid-19. Adanya preferensi pasar yang berbeda pada masa pandemi Covid-19 menjadi dasar utama bagi pelaku UMKM untuk melakukan adaptasi produk sesuai kebutuhan masyarakat di masa pandemi agar dapat menjaga eksistensi kinerja UMKM

2. Strategi adaptasi pemasaran berpengaruh signifikan terhadap kinerja UMKM di Kabupaten Mamuju pada masa pandemi Covid-19. Pembatasan pertemuan fisik menyebabkan para pelaku UMKM melakukan adaptasi pemasaran melalui pemanfaatan media sosial dan e-commerce untuk memasarkan produk secara daring sehingga UMKM tetap produktif dan berkinerja baik

3. Strategi adaptasi produk dan strategi adaptasi pemasaran berpengaruh signifikan secara simultan terhadap kinerja UMKM di Kabupaten Mamuju. 
Melalui proses adaptasi jenis dan kualitas produk serta program pemasaran yang sesuai kebutuhan pada masa pandemi maka pelaku UMKM dapat menjaga dan meningkatkan kinerjanya.

4. Faktor dominan yang memengaruhi kinerja UMKM di Kabupaten Mamuju pada masa pandemi yaitu strategi adaptasi pemasaran. Oleh karena itu maka adaptasi pemasaran merupakan prioritas apabila pelaku UMKM menghadapi penyesuaian regulasi pada masa pandemi

\section{SARAN}

Peneliti mengakui bahwa terdapat beberapa keterbatasan ataupun kekurangan dalam hasil penelitian yang diperoleh. Oleh karena itu beberapa saran yang dapat diberikan ialah sebagai berikut :

1. Untuk memperoleh informasi yang lebih mendalam terkait operasionalisasi strategi adaptasi yang dilakukan oleh UMKM maka peneliti selanjutnya disarankan menggunakan pendekatan kualitatif agar dapat mengkaji lebih lanjut mengenai strategi adaptasi UMKM

2. Peneliti selanjutnya dapat menggunakan pendekatan kuantitatif dengan menambahkan variabel lainnya yang dapat meningkatkan kinerja UMKM khususnya pada masa pandemi

\section{UCAPAN TERIMA KASIH}

Penulis mengucapkan terima kasih kepada Direktorat Sumberdaya Direktorat Jenderal Pendidikan Tinggi Kementerian Pendidikan, Kebudayaan, Riset, dan Teknologi yang telah memberi dukungan financial terhadap penelitian ini.

\section{DAFTAR PUSTAKA}

Ahimsa,H.S. (2003). Ekonomi Moral, Rasional, dan Politik dalam Industri Kecil di Jawa. Yogyakarta : Kepel Press.

Amri, Andi. (2020). Dampak Covid-19 terhadap UMKM di Indonesia. Jurnal Brand, 2(1): $123-130$.

Barisa, Wilda. (2021). Adaptasi Usaha Mikro Kecil Menengah (UMKM) di Masa Pandemi Covid 19. Jurnal Publicio, 3(1), 40-44.

Bhayangkari, S.K.W. (2011). Penerapan Standardisasi dan Adaptasi Sebagai Upaya Pengembangan Strategi Produk Pada Pemasaran Internasional. Mankeu, 1(3), 245258.

Halim, Abdul. (2020). Pengaruh Pertumbuhan Usaha Mikro, Kecil, dan Menengah terhadap Pertumbuhan Ekonomi Kabupaten Mamuju. GROWTH, 1(2), 157-172

Hidayat, Muhammad, Fitriani L., Andi W., Nurkhalik W.A., Nurhaeda Z. 2021. Factors Supporting Business and Its Distribution to Business Resilience In New Normal Era. Journal of Distribution Science, 19(11), 5-15.

Kurniati. (2015). Strategi Adaptasi Pedagang Angkringan dalam Mempertahankan Eksistensi Hidup Studi di Kawasan Jl. K.H. Ali Maksum Krapyak Yogyakarta (Perbandingan Antara Angkringan Tradisional versus Angkringan Modern. JESI, 5(2), 179-198.

Mandasari, D.J., Joko W., dan Sutrisno D. (2019). Strategi Pemasaran usaha Mikro, Kecil, dan Menengah (UMKM) Batik Magenda Tamanan Kabupaten Bondowoso. JPE, 13(1), 123-128. 
mamujukab.go.id. 21-08-2020. Bantuan UMKM dari Pemprov disalurkan, Wabup Mamuju Ungkap Terima Kasih. Diakses dari : http://mamujukab.go.id/bantuanumkm-dari-pemprov-di-salurkan-wabup-mamuju-ungkap-terimakasih/ pada Sabtu 24 Oktober 2020

Narto dan Gatot B. (2020). Penguatan Strategi Pemasaran Pudak di Tengah Pandemi Covid-19 untuk Meningkatkan Keunggulan Bersaing Usaha Mikro Kecil Menengah Kota Gresik. Jurnal INTECH, 6(1), 48-54.

Pakpahan, A. Kristian. (2020). Covid-19 dan Implikasi Bagi Usaha Mikro, Kecil, dan Menengah. JIHI Pacis 59-64.

Pearce, J.A. dan Robinson R.B. (2008). Manajemen Strategis. Buku 1 Edisi 10. Jakarta: Salemba Empat.

Rosita, Rahmi. (2020). Pengaruh Pandemi Covid-19 terhadap UMKM di Indonesia. Jurnal Lentera Bisnis, 9(2), 109-120.

Rosmadi, M. Lucky. (2020). Penerapan Strategi Bisnis di Masa Pandemi Covid-19. Jurnal Ekonomika, 4(1), 122-127.

Setiawan, L.H. dan I Wayan B. (2020). Analisis Strategi Pemasaran Handmade Tas UMKM AKA di Kelurahan Bubulak Kabupaten Bogor. Jurnal Pusat Inovasi Masyarakat, 2(5), 869-880.

Sugiyono. (2017). Metode Penelitian Kuantitatif, Kualitatif, dan R\&D. Bandung: Alfabeta.

Tandusan, Chevy F. (2015). Analisis Komparasi Efektivitas Penjualan Sebelum dan Sesudah Menggunakan Video Marketing Onlie Talk Fusion di Manado. Jurnal Riset Bisnis dan Manajemen, 3(2), 141-154.

Taufiqurokhman. (2016). Manajemen Strategik. Jakarta : FISIP Universitas Prof. Dr. Moestopo Beragama.

Utami, Diyah, Mutiah, \& A. Sudrajat. (2021). Adaptation Strategy of MSME (Micro, Small and Medium Enterprises) Actors in The Middle of Covid Pandemic (Study in Surabaya and Sidoarjo). METAFORA, 5(1), 52-57. 